\title{
The Effect of Bifidobacterium lactis on the Growth of Infants: A Pooled Analysis of Randomized Controlled Studies
}

\author{
Philippe G. Steenhout ${ }^{\mathrm{a}}$ Florence Rochat ${ }^{\mathrm{b}}$ Corinne Hager ${ }^{\mathrm{b}}$ \\ ${ }^{a}$ Nestlé Nutrition, Nestec Ltd., Vevey, and b Nestlé Research Center, Lausanne, Switzerland
}

\section{Key Words}

Bifidobacterium lactis - Body mass index - Breastfeeding •

Infant formula $\cdot$ Probiotics $\cdot$ Weight $\cdot$ Z-scores

\begin{abstract}
Background/Aims: Breast milk is the best source of nutrition for the growth of the newborn infant. It is therefore essential that mothers who cannot breastfeed or choose not to are provided with alternatives that closely match the composition and functionality of breast milk. This study aimed to investigate the growth effects of probiotic-supplemented formulas on both healthy and vulnerable populations of infants. Methods: A meta-analysis of data from 5 randomized controlled clinical trials that included infants fed formulas containing a probiotic Bifidobacterium lactis CNCM I-3446 was performed $(n=525)$. A sub-analysis was performed among infants of HIV-positive mothers $(n=120)$. Growth measurements (gain in weight and body mass index, BMI, from enrollment to 120 days) were compared between infants fed a formula containing $B$. lactis and those fed a control formula. Changes in length and Z-scores were also compared. Results: Formula with $B$. lactis was demonstrated to be at least as good as formula without $B$. lactis in the metaanalysis of 5 studies. The lower boundary of the $95 \%$ confidence interval $(\mathrm{Cl})$ of the differences in mean weight gain (95\% Cl 0.09-2.93 g/day) was above the predefined non-inferiority margin of $-3.0 \mathrm{~g} /$ day. Moreover, among infants with HIV-positive mothers, weight gain of those taking $B$. lactis was significantly higher than of those not taking $B$. lactis,
\end{abstract}

by $3.1 \mathrm{~g} /$ day $(95 \% \mathrm{Cl} 0.4-5.8 \mathrm{~g} /$ day, $\mathrm{p}=0.0226)$ and the BMI gains were significantly higher, by $6.4 \mathrm{~g} / \mathrm{m}^{2} /$ day $(95 \% \mathrm{Cl}$ $0.0 .3-12.5 \mathrm{~g} / \mathrm{m}^{2} /$ day, $\mathrm{p}=0.0400$ ). The corresponding weight for age and BMI Z-scores were also significantly higher, by $0.37(95 \% \mathrm{Cl} 0.03-0.71, \mathrm{p}=0.0308)$ and by $0.42(95 \% \mathrm{Cl} 0.02-$ $0.83, p=0.0377$ ), respectively, whereas differences in length gain or length-for-age Z-score were not significant. Among infants in the non-HIV mothers group, there were no significant differences between infants fed formulas with or without $B$. lactis, for any of the growth parameters. Conclusions: The analysis suggests that $B$. lactis may have a positive effect on growth in vulnerable populations, specifically in infants born to mothers with HIV.

Copyright $\odot 2009$ S. Karger AG, Basel

\section{Introduction}

Exclusive breast feeding up to 6 months of age is seen as the best way of feeding infants for optimum growth and development [1]. According to the World Health Organization (WHO) 1.5 million children die each year due to inadequate breastfeeding [2]. Several factors may contribute to the lack of adequate breastfeeding, such as poor education and support given to mothers [3], inability to produce sufficient breast milk $[4,5]$, and concomitant medication. A growing number of women are also not breastfeeding because of HIV infection and the risk of transmitting it to their infants [6]. It therefore remains imperative that alongside education and counseling,

\section{KARGER}

Fax +4161306 1234 E-Mail karger@karger.ch www.karger.com

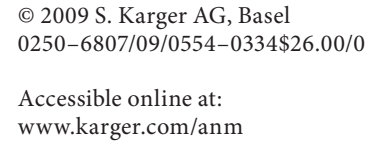

Philippe G. Steenhout

Nestlé Nutrition

Av. Reller 22

$\mathrm{CH}-1800$ Vevey (Switzerland)

Tel. +41 21924 2974, Fax +41 21924 4527, E-Mail philippe.steenhout@ nestle.com 
Table 1. Summary of trials

\begin{tabular}{|c|c|c|c|c|c|c|}
\hline Trial & $\begin{array}{l}\text { Year } \\
\text { started/ } \\
\text { completed }\end{array}$ & Location & $\begin{array}{l}\text { Maternal } \\
\text { HIV status }\end{array}$ & $\begin{array}{l}\text { Probiotic formulas } \\
\text { (CFU* B. lactis/g of powder) }\end{array}$ & Non-probiotic formulas & $\begin{array}{l}\text { Total number of } \\
\text { subjects (probiotic/ } \\
\text { non-probiotic) }\end{array}$ \\
\hline 1 & 2001 & S. Africa & positive & biologically acidified $\left(2 \times 10^{7}\right)$ & biologically acidified & $104(53 / 51)$ \\
\hline 2 & $2003 / 2004$ & S. Africa & positive & directly acidified $\left(2 \times 10^{7}\right)$ & directly acidified & $142(72 / 70)$ \\
\hline 3 & $2003 / 2005$ & Australia & negative & new NAN + LC-PUFAs $\left(2 \times 10^{7}\right)$ & new NAN & $111(53 / 58)$ \\
\hline 4 & $2000 / 2002$ & Italy & unknown & whey predominant $\left(3 \times 10^{7}\right)$ & whey predominant & $88(45 / 43)$ \\
\hline 5 & $2000 / 2001$ & USA & unknown & $\begin{array}{l}\text { reduced protein, partially hydrolyzed } \\
\text { whey }\left(2 \times 10^{7}\right)\end{array}$ & $\begin{array}{l}\text { reduced protein, partially } \\
\text { hyrdrolyzed whey }\end{array}$ & $80(40 / 40)$ \\
\hline
\end{tabular}

$\mathrm{CFU}=$ Colony-forming units; LC-PUFAs $=$ long-chain polyunsaturated fatty acids; $\mathrm{NAN}^{\circledR}=$ infant starter formula.

mothers who do not breastfeed are provided with alternatives that mimic the composition and functionality of breast milk.

The addition of probiotics to infant formulas is one of the adaptations aimed at improving the balance of the intestinal microbiota and health of formula-fed infants [7]. Probiotics are living non-pathogenic bacteria which when administered in adequate amounts confer health benefits on the host and have found wide application in healthcare and nutrition [8]. During the months prior to weaning, differences in the microbiota composition between breast-fed and formula-fed infants are apparent $[9$, 10]. In full-term infants, breast feeding induces the development of a microbiota rich in Bifidobacterium species. By contrast, formula-fed infants are often colonized by a more diverse microbiota, including Clostridium perfringens, Escherichia coli and Bacteroïdes in addition to bifidobacteria $[11,12]$. Probiotics have also been shown to be beneficial in the prevention [13] and treatment of diarrhea [14] in children and a study has shown that select probiotic strains may improve the growth of infants up to 6 months [15]. A study in preterm infants showed that supplementing infant formula with bifidobacteria decreases intestinal permeability and leads to increased head growth [16].

Despite studies suggesting that probiotics are well tolerated and safe $[17,18]$, the regulatory environments in Europe and the United States are vague with respect to the potential health benefits of probiotics in infant formula [19]. This is especially important for healthcare professionals who advise mothers on how to proceed once the decision not to breastfeed has been made.

We carried out a pooled analysis of data from studies on probiotic-supplemented formulas with the aim of eval- uating the effects of the probiotic Bifidobacterium lactis CNCM I-3446 on the growth of healthy infants and those who may be vulnerable to low or reduced early growth. For the latter group we chose children of mothers with HIV who, even if HIV negative, tend to have lower birth weights [20], reduced early growth [21] and an increased risk of mortality and morbidity during the first few months of life [22] than children of uninfected mothers.

\section{Methods}

\section{Studied Infant Populations}

Data from 5 randomized controlled double-blind clinical trials (table 1 and fig. 1) were analyzed by meta-analysis and pooled analysis. The 5 studies were originally designed to determine the growth effects of various infant formulas containing the probiotic $B$. lactis. The studies were selected because of the availability of raw data and the similarity in study design.

Two studies conducted in South Africa [23, 24] involved infants born to mothers who were diagnosed with HIV, and 3 other studies (in Australia [25], Italy [26, 27] and the United States [28]) were of infants whose mothers were not diagnosed as having HIV infection (table 1). With the exception of maternal HIV status, the 5 trials had similar inclusion and exclusion criteria. Infants were exclusively formula-fed and enrolled before the age of 14 days, except for 1 study in the non-HIV group (trial 4) where the infants were enrolled before the age of 28 days.

Inclusion criteria for the HIV studies were a positive maternal HIV status, a healthy full-term newborn and a birth weight of 2,500-4,200 g. In one of the HIV studies (trial 2), the administration of nevirapine to mothers and infants was an inclusion criterion. Only infants who were HIV negative at 6 weeks of age were considered for the pooled analysis. Inclusion criteria for the nonHIV group were a healthy full-term newborn and a birth weight of 2,500-4,500 g. Infants who had major deformities or illnesses or who required intensive care after birth were excluded from all studies. 
Fig. 1. Distribution of infants in the metaanalysis.

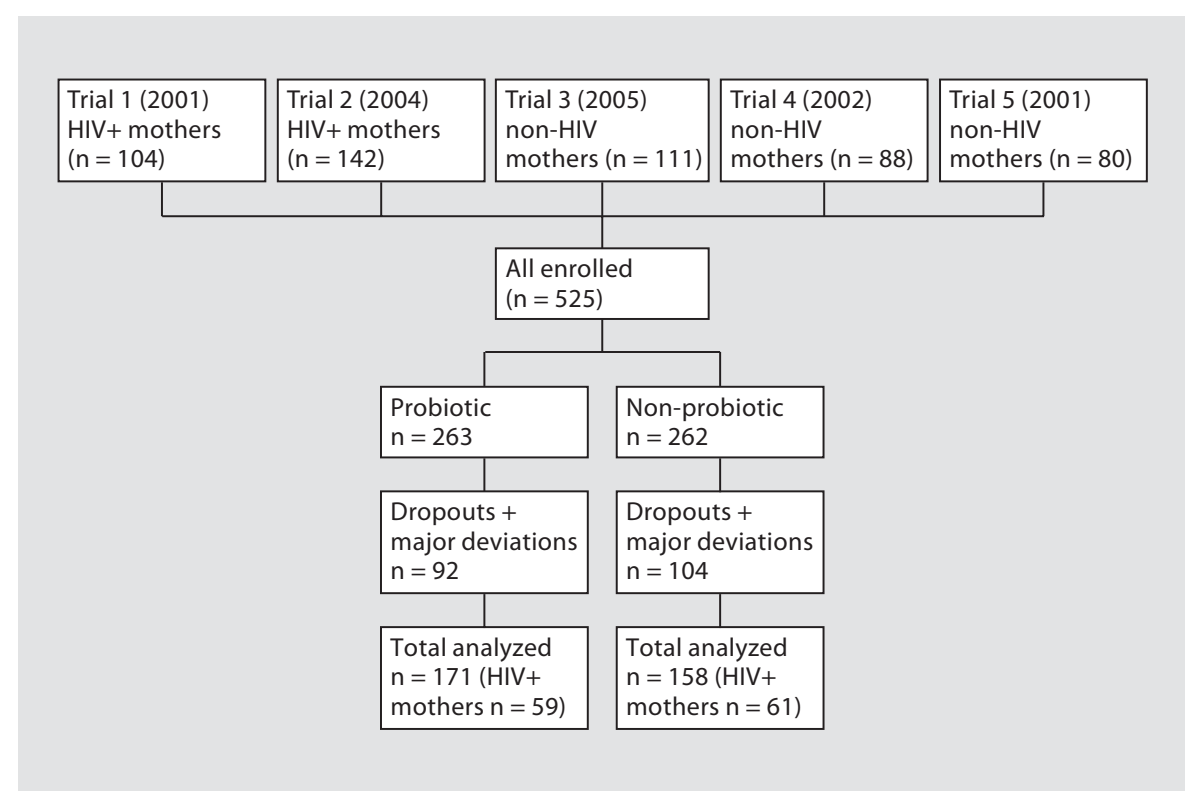

In accordance with the Helsinki declaration of 1975 (revised 1983) on experimentation on human subjects, the procedures followed in the 5 studies were in compliance with the ethical standards of the responsible institutional and regional committees. Parents or guardians of the subjects gave their informed consent.

\section{Original Data Collection}

In all studies, similar methods were used to obtain anthropometric data. Infants were weighed without clothing to the nearest $10 \mathrm{~g}$. For the individual trials, the same scales were used for all infants and visits, and were calibrated as per the manufacturer's recommendations. Infant length was measured to the nearest $1 \mathrm{~mm}$ using standardized length boards. At least 2 trained personnel were present to maintain full body extension and flexion of the feet during measurement. Measurements were made at birth and at 120 days after intake of the study formula.

\section{Pooled Data}

Only data from infants who were given formulas with the probiotic B. lactis CNCM I-3446 (2-3 × $10^{7}$ colony forming units per gram of powder) and their corresponding control formulas without $B$. lactis entered the pooled analysis. Only subjects with available data at 120 days and without having major deviations (HIVpositive infants or not compliant with exclusive feeding were excluded) were included in the analysis. The 5 studies were pooled and analyzed using meta-analysis methodology to determine the growth effect of the formula with $B$. lactis versus the control formula. A subgroup analysis was carried out according to the HIV status of mothers in order to look at the probiotic effect in vulnerable populations. The primary outcome for the pooled analysis was weight gain (g/day) calculated as the increase in weight over the study period (enrollment to 120 days) divided by the number of days. Secondary outcomes were changes in length per day $(\mathrm{cm} /$ day) and in body mass index (BMI) per day ( $\mathrm{g} / \mathrm{m}^{2} /$ day). Z-scores for weight, length and BMI based on the WHO reference were also calculated [29].

\section{Statistical Analysis}

A meta-analysis using individual data was performed and a mixed model with birth values, baseline values and sex as fixed factors and study effect as random factor was used to compare the weight, length and BMI gains and corresponding Z-scores between infants receiving $B$. lactis-containing formulas and control formulas. Subgroup analysis according to the mothers' HIV status was performed using similar model. No direct comparisons were made between the HIV and non-HIV groups.

\section{Results}

Birth weight, length and BMI values were similar between infants in the group assigned to receive $B$. lactis supplemented and control formulas in the 5 pooled groups (table 2). Similarly in the sub-analysis, at birth these anthropometric measurements were similar between infants receiving $B$. lactis supplemented and control formulas in both the group of infants with HIV-positive mothers and those with HIV-negative mothers (table 3). Infants from HIV-positive mothers tended to have a lower weight and $\mathrm{BMI}$ and lower corresponding Z-scores at birth than infants from non-HIV mothers (table 3).

Effect of $B$. lactis in growth development was demonstrated from the meta-analysis, with 4 trials showing fa- 
Table 2. Birth characteristics of infants from the 5 pooled studies

\begin{tabular}{|c|c|c|c|c|c|c|}
\hline & \multicolumn{3}{|c|}{ Probiotic $(\mathrm{n}=171)$} & \multicolumn{3}{|c|}{ Non-probiotic $(\mathrm{n}=158)$} \\
\hline & $\mathrm{n}$ & mean & $\mathrm{SD}$ & $\mathrm{n}$ & mean & $\mathrm{SD}$ \\
\hline Male/female (\% male) & $87 / 84(51)$ & & & $74 / 84(47)$ & & \\
\hline Weight at birth, g & 170 & 3,333 & 437 & 157 & 3,245 & 431 \\
\hline Weight-for-age Z-score & 170 & 0.05 & 0.9 & 157 & -0.12 & 0.93 \\
\hline Length at birth, $\mathrm{cm}$ & 169 & 49.9 & 2.13 & 157 & 49.6 & 2.19 \\
\hline Length-for-age Z-score & 169 & 0.19 & 1.14 & 157 & 0.06 & 1.18 \\
\hline BMI at birth, $\mathrm{kg} / \mathrm{m}^{2}$ & 169 & 13.4 & 1.30 & 157 & 13.2 & 1.37 \\
\hline BMI Z-score & 169 & -0.05 & 1.04 & 157 & -0.22 & 1.11 \\
\hline
\end{tabular}

vorable growth effects of $B$. lactis and one study showing an unfavorable growth effect of $B$. lactis (fig. 2). A new formula is considered to be as good as a reference if the lower margin of the $95 \%$ CI of mean weight gain is not lower than $-3 \mathrm{~g} /$ day. From the pooled analysis the difference in mean weight gain from enrollment up to 120 days between the $B$. lactis-containing formula and the control formula group was $+1.5 \mathrm{~g} /$ day $(95 \%$ CI $0.09-2.93, \mathrm{p}=$ 0.0368; table 4).

Among infants with HIV-positive mothers, mean weight gain from enrollment up to 120 days was significantly higher in infants taking $B$. lactis compared with those not taking B. lactis (table 5). Similarly, changes in weight-for-age $\mathrm{Z}$-scores were significantly higher in infants taking formulas containing $B$. lactis (table 5) while length for age $\mathrm{Z}$-scores changes did not show any significant differences (table 5). There was a significant difference in the mean gain in BMI values between the group fed formula containing $B$. lactis and the control group as well as a significant difference in gain in BMI Z-scores, with a higher change in BMI Z-scores in the B. lactis group compared to the control group (table 5). By contrast, there were no significant differences in any of these growth parameters between the $B$. lactis and the control groups among infants with HIV-negative mothers (table 6). Since the lower boundary of the $95 \%$ CI of the difference in mean weight gain $(-1.09 \mathrm{~g} /$ day $)$ was above the non-inferiority margin of $-3.0 \mathrm{~g} /$ day (table 5), these data demonstrate that the formulas containing $B$. lactis promote growth of infants as well as control formulas that lack B. lactis.

Morbidity was coded with particular attention to gastrointestinal disorders. The most frequent terms were gastroenteritis, diarrhea, gastroesophageal reflux and vomiting, and together they were experienced in about $24 \%$ of infants in the probiotic group compared to $29 \%$ in the non-probiotic group (relative risk $(\mathrm{RR})=0.89,95 \% \mathrm{CI}$

Probiotics and Infant Growth

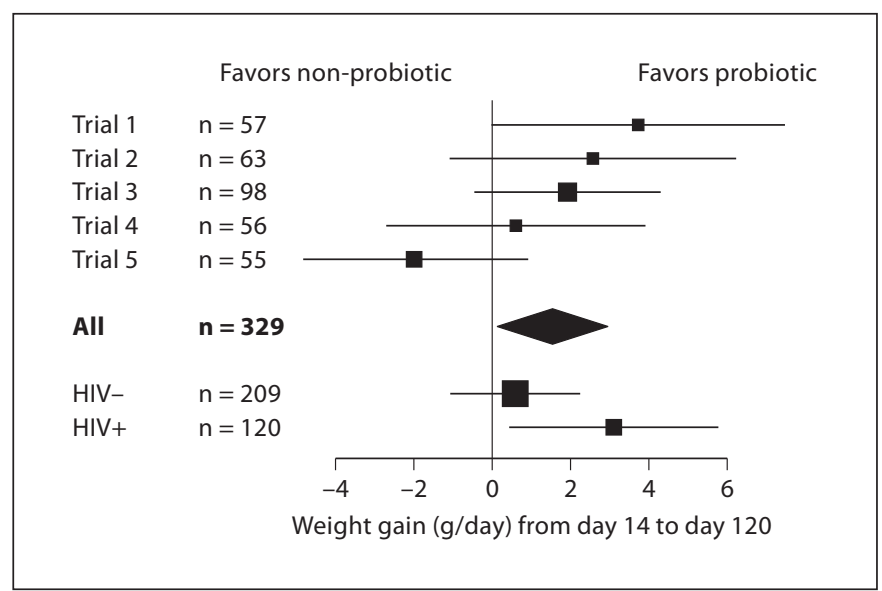

Fig. 2. Forest plot of difference in means of weight gain (g/day) from the B. lactis-containing formula group minus the control formula group. The box sizes reflect the relative sample sizes of the individual studies; horizontal lines represent 95\% CIs. Diamond represents the pooled point estimate and 95\% CI. The last 2 lines represent the results according to mother's HIV status. Estimates greater than a value of 0 suggest a favorable weight gain with the B. lactis formula group.

$0.70-1.13, \mathrm{p}=0.3513$, from the pooled analysis). Within the HIV-positive mothers groups, the RR of the probiotic group versus the control group was $0.79,95 \%$ CI $0.55-1.14$, $\mathrm{p}=0.3631$ and $0.94,95 \%$ CI $0.69-1.29, \mathrm{p}=0.7237$.

\section{Discussion}

Analysis of the data pooled from 5 studies with similar design showed that infants fed formulas containing the probiotic $B$. lactis had similar growth (weight gain per 
Table 3. Birth characteristics according to maternal HIV status

\begin{tabular}{|c|c|c|c|c|c|c|c|c|c|c|c|c|}
\hline & \multicolumn{6}{|c|}{ Mother HIV positive $(\mathrm{n}=120)$} & \multicolumn{6}{|c|}{ Mother non-HIV $(\mathrm{n}=209)$} \\
\hline & \multicolumn{3}{|c|}{ probiotic $(n=59)$} & \multicolumn{3}{|c|}{ non-probiotic $(\mathrm{n}=61)$} & \multicolumn{3}{|c|}{ probiotic $(\mathrm{n}=112)$} & \multicolumn{3}{|c|}{ non-probiotic $(\mathrm{n}=97)$} \\
\hline & $\mathrm{n}$ & mean & SD & $\mathrm{n}$ & mean & SD & $\mathrm{n}$ & mean & SD & $\mathrm{n}$ & mean & SD \\
\hline Male/female (\% male) & \multicolumn{3}{|c|}{$36 / 23^{\mathrm{a}}(61)$} & \multicolumn{3}{|c|}{$29 / 32^{\mathrm{a}}(48)$} & \multicolumn{3}{|c|}{$51 / 61(46)$} & \multicolumn{3}{|c|}{$45 / 52(46)$} \\
\hline Weight at birth, $g$ & 58 & 3,199 & 367 & 60 & 3,150 & 401 & 112 & 3,403 & 455 & 97 & 3,304 & 440 \\
\hline Weight-for-age Z-score & 58 & -0.25 & 0.78 & 60 & -0.33 & 0.86 & 111 & 0.21 & 0.94 & 97 & 0.01 & 0.96 \\
\hline Length at birth, $\mathrm{cm}$ & 58 & 49.8 & 1.83 & 60 & 49.6 & 2.36 & 111 & 49.9 & 2.3 & 97 & 49.6 & 2.1 \\
\hline Length-for-age Z-score & 58 & 0.13 & 1.00 & 60 & 0.05 & 1.25 & 111 & 0.22 & 1.21 & 97 & 0.06 & 1.13 \\
\hline BMI at birth, $\mathrm{kg} / \mathrm{m}^{2}$ & 58 & 12.9 & 1.28 & 60 & 12.8 & 1.25 & 111 & 13.6 & 1.2 & 97 & 13.4 & 1.4 \\
\hline BMI Z-score & 58 & -0.47 & 1.08 & 60 & -0.53 & 1.07 & 111 & 0.17 & 0.96 & 97 & -0.04 & 1.11 \\
\hline
\end{tabular}

a Data unavailable for 1 infant in each group.

Table 4. Anthropometric parameters of infants in the B. lactis-containing formula and control formula groups from the 5 pooled studies

\begin{tabular}{|c|c|c|c|c|c|c|c|}
\hline \multirow[t]{2}{*}{ Up to 120 days } & \multirow{2}{*}{$\begin{array}{l}\text { Probiotic } \\
\text { means }[95 \% \mathrm{CI}]\end{array}$} & \multirow{2}{*}{$\begin{array}{l}\text { Non-probiotic } \\
\text { means }[95 \% \mathrm{CI}]\end{array}$} & \multicolumn{5}{|c|}{ Probiotic vs. non-probiotic } \\
\hline & & & $\begin{array}{l}\text { diff. } \\
\text { means }\end{array}$ & SE & $\begin{array}{l}95 \% \mathrm{CI} \\
\text { lower }\end{array}$ & $\begin{array}{l}95 \% \mathrm{CI} \\
\text { upper }\end{array}$ & $\mathrm{p}$ value \\
\hline Weight gain, g/day & $31.3[30.34 ; 32.34]$ & $29.8[28.80 ; 30.84]$ & 1.5 & 0.72 & 0.09 & 2.93 & 0.0368 \\
\hline Weight Z-score change & $0.47[0.34 ; 0.59]$ & $0.28[0.15 ; 0.41]$ & 0.18 & 0.09 & 0.005 & 0.36 & 0.0432 \\
\hline Length gain, $\mathrm{cm} / \mathrm{month}$ & $3.19[3.12 ; 3.26]$ & $3.17[3.10 ; 3.24]$ & 0.02 & 0.05 & -0.08 & 0.11 & 0.7284 \\
\hline Length Z-score change & $0.22[0.10 ; 0.33]$ & $0.19[0.08 ; 0.31]$ & 0.03 & 0.08 & -0.14 & 0.18 & 0.7881 \\
\hline BMI gain, $\mathrm{g} / \mathrm{m}^{2} /$ day & $37.6[35.26 ; 39.92]$ & $34.16[31.78 ; 36.54]$ & 3.44 & 1.68 & 0.13 & 6.75 & 0.0418 \\
\hline BMI Z-score change & $0.48[0.32 ; 0.64]$ & $0.24[0.08 ; 0.40]$ & 0.24 & 0.11 & 0.02 & 0.46 & 0.0329 \\
\hline
\end{tabular}

day from enrollment to 120 days) compared with those fed control formulas lacking B. lactis. On the other hand, a sub-analysis of vulnerable infants born to mothers with HIV (but not in infants born to healthy mothers) feeding infants formulas containing $B$. lactis led to significantly higher weight and BMI gains.

The study considered the per protocol population. Although $30 \%$ of the children were excluded from the per protocol population, the dropouts do not seem to be due to treatment. High dropout rates in trials of non-medicinal products, especially among healthy infants, are not unusual, and in the studies analyzed here there was not a significant difference in the number of infants who dropped out from the probiotic formula-fed and nonprobiotic formula-fed groups. In fact, the percentage dropout was higher (albeit not significant) in the nonprobiotic formula groups (42 and 39\% among infants born to HIV-negative and HIV-positive mothers, respectively) compared with the probiotic formula groups (32 and $34 \%$ among infants born to HIV-negative and HIVpositive mothers, respectively), suggesting an absence of treatment (probiotic)-related dropouts.

There are limitations in collating and analyzing data from different studies. The main difference between the trials was that the formulas used differed with respect to acidification and protein content. Furthermore, one of the probiotic formulas (trial 3) in the non-HIV group contained long-chain polyunsaturated fatty acids which were not found in the comparator formula. Nevertheless, apart from trial 3, within each trial the probiotic and comparator formulas were identical except for the presence of probiotics in one. Therefore, we do not expect the differences in the formulas to have affected the comparisons between infants receiving formula con- 
Table 5. Anthropometric parameters for group with HIV-positive mothers $(\mathrm{n}=120)$

\begin{tabular}{|c|c|c|c|c|c|c|c|}
\hline \multirow[t]{2}{*}{ Up to 120 days } & \multirow{2}{*}{$\begin{array}{l}\text { Probiotic } \\
\text { means }[95 \% \mathrm{CI}]\end{array}$} & \multirow{2}{*}{$\begin{array}{l}\text { Non-probiotic } \\
\text { means }[95 \% \mathrm{CI}]\end{array}$} & \multicolumn{5}{|c|}{ Probiotic vs. non-probiotic } \\
\hline & & & $\begin{array}{l}\text { diff. } \\
\text { means }\end{array}$ & SE & $\begin{array}{l}95 \% \text { CI } \\
\text { lower }\end{array}$ & $\begin{array}{l}\text { 95\% CI } \\
\text { upper }\end{array}$ & $\mathrm{p}$ value \\
\hline Weight gain, g/day & $34.7[32.79 ; 36.63]$ & $31.6[29.71 ; 33.44]$ & 3.1306 & 1.3548 & 0.4477 & 5.8135 & 0.0226 \\
\hline Weight Z-score change & $0.92[0.68 ; 1.16]$ & $0.54[0.31 ; 0.78]$ & 0.3721 & 0.1703 & 0.0349 & 0.7093 & 0.0308 \\
\hline Length gain, $\mathrm{cm} / \mathrm{month}$ & $3.16[3.03 ; 3.29]$ & $3.11[2.98 ; 3.24]$ & 0.0509 & 0.0933 & -0.1338 & 0.2356 & 0.5863 \\
\hline Length Z-score change & $0.20[-0.03 ; 0.42]$ & $0.10[-0.12 ; 0.32]$ & 0.0964 & 0.1590 & -0.2185 & 0.4113 & 0.5454 \\
\hline BMI gain, $\mathrm{g} / \mathrm{m}^{2} /$ day & $47.20[42.85 ; 51.56]$ & $40.82[36.59 ; 45.05]$ & 6.3838 & 3.0744 & 0.2956 & 12.4720 & 0.0400 \\
\hline BMI Z-score change & $1.12[0.82 ; 1.40]$ & $0.68[0.40 ; 0.96]$ & 0.4280 & 0.2036 & 0.0247 & 0.8313 & 0.0377 \\
\hline
\end{tabular}

A mixed model was used, with sex, birth and enrollment values considered as fixed effects and study as random effect.

Table 6. Anthropometric parameters for group with HIV-negative mothers $(\mathrm{n}=209)$

\begin{tabular}{|c|c|c|c|c|c|c|c|}
\hline \multirow[t]{2}{*}{ Up to 120 days } & \multirow{2}{*}{$\begin{array}{l}\text { Probiotic } \\
\text { means }[95 \% \mathrm{CI}]\end{array}$} & \multirow{2}{*}{$\begin{array}{l}\text { Non-probiotic } \\
\text { means }[95 \% \mathrm{CI}]\end{array}$} & \multicolumn{5}{|c|}{ Probiotic vs. non-probiotic } \\
\hline & & & $\begin{array}{l}\text { diff. } \\
\text { means }\end{array}$ & SE & $\begin{array}{l}95 \% \text { CI } \\
\text { lower }\end{array}$ & $\begin{array}{l}95 \% \mathrm{CI} \\
\text { upper }\end{array}$ & $\mathrm{p}$ value \\
\hline Weight gain, g/day & $29.15[27.99 ; 30.29]$ & $28.62[27.45 ; 29.79]$ & 0.5242 & 0.8165 & -1.0855 & 2.1339 & 0.5215 \\
\hline Weight Z-score change & $0.20[0.06 ; 0.34]$ & $0.12[-0.02 ; 0.0 .27]$ & 0.0766 & 0.1036 & -0.1278 & 0.2809 & 0.4609 \\
\hline Length gain, $\mathrm{cm} / \mathrm{month}$ & $3.22[3.14 ; 3.29]$ & $3.21[3.13 ; 3.29]$ & 0.0035 & 0.0545 & -0.1040 & 0.1109 & 0.9489 \\
\hline Length Z-score change & $0.26[0.14 ; 0.38]$ & $0.26[0.14 ; 0.39]$ & -0.0025 & 0.0851 & -0.1702 & 0.1652 & 0.9766 \\
\hline BMI gain, $\mathrm{g} / \mathrm{m}^{2} /$ day & $31.54[28.80 ; 34.28]$ & $29.80[26.97 ; 32.64]$ & 1.7376 & 1.9774 & -2.1613 & 5.6365 & 0.3806 \\
\hline BMI Z-score change & $0.09[-0.09 ; 0.27]$ & $-0.04[-0.23 ; 0.15]$ & 0.1291 & 0.1325 & -0.1322 & 0.3905 & 0.3311 \\
\hline
\end{tabular}

A mixed model was used, with sex, birth and enrollment values considered as fixed effects and study as random effect.

taining probiotics with those receiving control formulas.

The analysis raised important questions on probiotic growth effects in different populations. The 2 trials involving infants of HIV-positive mothers were set in a developing country (South Africa), whereas the trials with infants of the non-HIV group were set in developed countries (Australia, Italy, and the United States). Since the risk of diarrhea, which may have an effect on growth, is higher in developing countries, the potential beneficial effects of probiotics on growth may be greater there. Thus, it is possible that general health conditions such as immunity of the infants in the HIV studies, which took place in South Africa, may have been a factor influencing the outcome (effect of the probiotic on growth).

In conclusion, this study suggests that although there was no effect of $B$. lactis on the growth of healthy infants,
B. lactis may have had a potential benefit of improving growth in a population of vulnerable infants with mothers who were HIV positive where the risk of faltering growth is greater. As this pooled analysis was carried out on $B$. lactis the results may not be applicable to other probiotic strains. However, the findings, which require confirmation from larger trials, are a major step towards understanding the role of probiotics in infant formula.

\section{Acknowledgments}

The authors would like to thank Cynthia A. Brown (Nestlé Nutrition USA), Florilène Bouisset, Juliet Farrar and Jean-Claude Maire (Nestlé Research Center, Lausanne, Switzerland), for reviewing the manuscript at various stages and Nacho Mbaeliachi (HPM Geneva) for his editorial support. This study was sponsored by Nestlé Nutrition - Nestec Ltd. (Vevey, Switzerland). 


\section{References}

1 WHO: Infant and young child nutrition resolution 54.2 of the World Health Assembly. Resolutions and Decisions of 54th World Health Assembly, 14-22 May 2001.

2 WHO: Global strategy for infant and young child feeding. Resolutions and Decisions of 54th World Health Assembly, 14-22 May 2001.

>3 Kuan LW, Britto M, Decolongon J, Schoettker PJ, Atherton HD, Kotagal UR: Health system factors contributing to breastfeeding success. Pediatrics 1999;104:e28.

$\checkmark 4$ Marchand L, Morrow MH: Infant feeding practices: understanding the decision-making process. Fam Med 1994;26:319-324.

$\checkmark 5$ Simopoulos AP, Grave GD: Factors associated with the choice and duration of infantfeeding practice. Pediatrics 1984;74:603614.

-6 Orne-Gliemann J, Mukotekwa T, Miller A, Perez F, Glenshaw M, Nesara P, Dabis F: Community-based assessment of infant feeding practices within a programme for prevention of mother-to-child HIV transmission in rural Zimbabwe. Public Health Nutr 2006;9:563-569.

-7 Riva E, Verduci E, Agostoni C, Giovannini M: Closer to the gold standard: an appraisal of formulae available in Italy for use in formula-fed infants. J Int Med Res 2005;33:595611.

>8 Bongaerts G, Severijnen R, Timmerman H: Effect of antibiotics, prebiotics and probiotics in treatment for hepatic encephalopathy. Med Hypotheses 2005;64:64-68.

$\checkmark 9$ Harmsen HJ, Wildeboer-Veloo AC, Raangs GC, Wagendorp AA, Klijn N, Bindels JG, Welling GW: Analysis of intestinal flora development in breast-fed and formula-fed infants by using molecular identification and detection methods. J Pediatr Gastroenterol Nutr 2000;30:61-67.

10 Wharton BA, Balmer SE, Scott PH: Sorrento studies of diet and fecal flora in the newborn. Acta Paediatr Jpn 1994;36:579-584.

-11 Balmer SE, Wharton BA: Diet and faecal flora in the newborn: breast milk and infant formula. Arch Dis Child 1989;64:16721677.
12 Penders J, Vink C, Driessen C, London N, Thijs C, Stobberingh EE: Quantification of Bifidobacterium spp., Escherichia coli and Clostridium difficile in faecal samples of breast-fed and formula-fed infants by realtime PCR. FEMS Microbiol Lett 2005;243: 141-147.

13 Szajewska H, Mrukowicz JZ: Probiotics in the treatment and prevention of acute infectious diarrhea in infants and children: a systematic review of published randomized, double-blind, placebo-controlled trials. J Pediatr Gastroenterol Nutr 2001;33(suppl 2): S17-S25.

14 Salminen S, Isolauri E: Intestinal colonization, microbiota, and probiotics. J Pediatr 2006;149:S115-S120.

15 Vendt N, Grunberg H, Tuure T, Malminiemi O, Wuolijoki E, Tillmann V, Sepp E, Korpela R: Growth during the first 6 months of life in infants using formula enriched with Lactobacillus rhamnosus GG: double-blind, randomized trial. J Hum Nutr Diet 2006;19:5158.

16 Stratiki Z, Costalos C, Sevastiadou S, Kastanidou O, Skouroliakou M, Giakoumatou A, Petrohilou V: The effect of a bifidobacter supplemented bovine milk on intestinal permeability of preterm infants. Early Hum Dev 2007;83:575-579.

-17 Puccio G, Cajozzo C, Meli F, Rochat F, Grathwohl D, Steenhout P: Clinical evaluation of a new starter formula for infants containing live Bifidobacterium longum BL999 and prebiotics. Nutrition 2007;23:1-8.

18 Weizman Z, Alsheikh A: Safety and tolerance of a probiotic formula in early infancy comparing two probiotic agents: a pilot study. J Am Coll Nutr 2006;25:415-419.

19 Scientific Committee on Food: Report of the Scientific Committee on Food on the revision of essential requirements of infant formulae and follow-on formulae. Brussels, European Commission, 2003.

20 Sombie I, Nacro B, Tiendrebeogo S, Dao B, Cartoux M, Meda N, Ky-Zerbo O, Dabis F, Mandelbrot L, Van de Perre P: Maternal HIV infection and the anthropometric characteristics of children at birth in Burkina Faso. DITRAME Study Group (in French). Santé 1999;9:173-177.

-21 Makasa M, Kasonka L, Chisenga M, Sinkala M, Chintu C, Filteau S: Early growth of infants of HIV-infected and uninfected Zambian women. Trop Med Intl Health 2007;12: 594-602.
22 Kuhn L, Kasonde P, Sinkala M, Kankasa C, Semrau K, Scott N, Tsai WY, Vermund SH, Aldrovandi GM, Thea DM: Does severity of HIV disease in HIV-infected mothers affect mortality and morbidity among their uninfected infants? Clin Infect Dis 2005;41:16541661.

23 Urban MF, Bolton KD, Mokhachane M, Mphahlele RM, Bomela HN, Monaheng L, Beckh-Arnold E, Cooper PA: Growth of infants born to HIV-infected women when fed a biologically acidified starter formula with and without probiotics. S Afr J Clin Nutr 2008;21:28-32.

24 Velaphi SC, Cooper PA, Bolton KD, Mokhachane M, Mphahlele RM, BeckhArnold E, Monaheng L, Haschke-Becher E: Growth and metabolism of infants born to women infected with human immunodeficiency virus and fed acidified whey-adapted starter formulas. Nutrition 2008;24:203211.

25 Gibson RA, Barclay D, Marshall H: Safety of supplementing infant formula with longchain polyunsaturated fatty acids and Bifidobacterium lactis in term infants: a randomised controlled trial. Br J Nutr 2009;101: 1706-1713.

26 Rochat F, Brown C, Hager C, Puccio G, Fazzolari-Nesci A, Barclay D, Haschke F: Effect of a formula with adapted protein profile on intestinal microbiota and growth of infants. J Pediatr Gastroenterol Nutr 2005;41:508.

27 Rochat F, Cherbut C, Barclay D: A whey-predominant formula induces fecal microbiota similar to that found in breast-fed infants. Nutr Res 2007;27:735-740.

28 Zeigler EE, Jeter JM, Drulis JM, Nelson SE, Haschke F, Steenhout P, Brown C, Maire JC, Hager C: Formula with reduced content of improved, partially hydrolzed protein and probiotics: infant growth and health. Monatsschr Kinderheilkd 2003;151:S65-S71.

29 WHO Anthro 2005 software. www.who.int/ childgrowth/software/en (accessed September 8, 2009). 